NOTICE: This is the author's version of a work that was accepted for publication in International Journal of Cardiology. Changes resulting from the publishing process, such as peer review, editing, corrections, structural formatting and other quality control mechanisms may not be reflected in this document. Changes may have been made to this work since it was submitted for publication. A definitive version was subsequently published in International Journal of Cardiology, Volume 168, Issue 2, 30 September 2013, Pages 760-764. http://dx.doi.org/10.1016/j.ijcard.2012.09.235 


\section{Cardiovascular health status in Chinese adults in urban areas: analysis of the Chinese Health Examination Database 2010}

Hai-Yun $\mathrm{Wu}^{1}$, Zhonghua Sun ${ }^{2}$, Dong-Ping $\mathrm{Cao}^{3}$, Liu-Xin Wu ${ }^{4}$, Qiang Zeng ${ }^{5]}$

1. Institute of Geriatric Cardiology, Chinese PLA General Hospital, Beijing 100853, China

2. Discipline of Medical Imaging, Department of Imaging and Applied Physics, Curtin University of Technology, Perth, Western Australia, Australia

3. The $306^{\text {th }}$ Hospital of Chinese PLA, Beijing 100101, China

4. Institute of Aviation Medicine, Chinese PLA Air Force, Beijing 100036, China

5. International Health Center, Chinese PLA General Hospital, Beijing 100853, China

\section{Corresponding author}

Dr Hai-Yun Wu, Institute of Institute of Geriatric Cardiology, Chinese PLA General Hospital, Beijing 100853, China

Tel/Fax: +861066936756

Email: why46301@163.com 


\section{Abstract}

Background: The American Heart Association (AHA) recently developed definitions of cardiovascular health for adults and children based on 7 cardiovascular disease risk factors or health behaviors. We applied this new construct to examine the cardiovascular health status in adult Chinese urban residents. Methods: Data of 1,012,418 subjects aged 20-65 years (55\% were men; mean age, 42.4 years) who received health examination at 58 health examination centers across China was analyzed. The AHA ideal health behaviors index and ideal health factors index were evaluated among the subjects. Results: Only $0.6 \%$ of male and $2.6 \%$ female subjects met all 7 health components, and only 39.1\% subjects met 5 or more components of ideal cardiovascular health. The prevalence of "ideal”, "intermediate" and "poor" cardiovascular health was 1.5\%, 33.9\% and 64.6\%, respectively. Conclusion: About two-thirds adult Chinese urban population has "poor" cardiovascular health. Comprehensive individual and population-based interventions must be developed to improve cardiovascular health status in China.

Keywords: Cardiovascular disease; epidemiology; risk factors; health assessment 


\section{Introduction}

Cardiovascular disease (CVD), principally stroke and coronary heart disease (CHD), is the leading cause of death in China and is expected to increase with further economic development, urbanization, aging of the population, and changes in diet and physical activity [1-3]. For decades, it has been believed that effective CVD prevention strategies must embrace both high-risk and population strategies; and more recently, the concept of "primordial prevention" which was considered as a strategy to prevent the development of risk factors in the first place, has been widely accepted and is also reflected in China's CVD prevention guidelines[4,5]. In 2010, the American Heart Association (AHA) developed definitions of "ideal," "intermediate," and "poor" cardiovascular health for adults and children based on 7 CVD risk factors or health behaviors [6]. Several recent studies have found extremely low prevalence of ideal cardiovascular health in the US adult populations [7-9].

We believe this new construct developed by AHA might be also useful and even more applicable in China where levels of CVD risk factors, except that of smoking, are still relatively low as compared to those in the United States but are elevating rapidly, and it is important to quantify the proportion of the population at different status of cardiovascular health. Such data would provide a context for policy planners and health promotion programs, an understanding of the size of the population in need of targeted interventions, and a baseline for international and longitudinal comparisons.

The present study reports the prevalence of ideal, intermediate and poor 
cardiovascular health among 1 million young and middle-aged Chinese adults by analyzing the Chinese Health Examination Database 2010, a cross-sectional dataset of more than 1.6 health examinees.

\section{METHODS}

\section{Study population}

In 2009, the Chinese Society of Health Management initiated the Chinese Health Examination Database (CHED). A total of 58 health examination centers covering 24 provinces, autonomous regions, and municipalities across China (Figure 1), which use computerized software to enter and manage data and to provide automated health risk assessment and individualized health promotion advice had participated. Data were entered or imported into and managed by Microsoft Excel at each center, then sent to the information center designated by the Chinese Society of Health Management for further checking and data merging [10].

The health examination procedure in these participated centers usually includes a series of medical tests for blood, urine, body measurements, functional tests, physical examination, and a questionnaire for lifestyle and medical history. The form and number of items of the questionnaires used by these centers are slightly different, but most of them are based on the China National Nutrition and Health Survey 2002 [11] questionnaire and all include questions addressing the examinees' daily intake of vegetables and fruits, animal meat, fish, preference for salty or non-salty food, as well as their weekly participation time in physical activity. 
By the end of October 2010, data of 1,674,846 Chinese health examinees (884,786 male and 790, 060 female) who had health examination at the participating health examination centers during the year of 2010 were collected. For the present study, we purposely excluded individuals who were younger than 20 years $(n=16,428)$ or older than 65 years $(n=424,368)$ as well as those who had missing values for variables used in the analyses (mostly because of missing or incalculable data on diet and physical activity, $n=221,632$ ), resulting in a total of 1,012,418 subjects (including 546,485 men and 465,933 women) eligible for analysis. Although prevalence of healthy behaviors and factors are known to decrease with aging [12, 13], several longitudinal studies have reported that it is feasible for middle- and older-aged individuals to maintain or even adopt a healthy lifestyle pattern that is associated with considerable CVD, stroke, and all-cause mortality benefits [14-16]. Thus, this study only focused on the middle-aged adults with regard to the cardiovascular health status.

Participants were stratified by age into 5 groups: 20-29 years, 30-39 years, 40-49 years, 50-59 years, and 60-65 years. Region where participants inhabit was categorized as South of North China.

\section{Cardiovascular health variables and definition}

The AHA defines cardiovascular health based on 4 health behaviors (smoking, body mass index, physical activity and diet and 3 health factors (total cholesterol, blood pressure, and untreated fasting glucose) [6]. For the present study, we adapted the AHA definitions and classified each cardiovascular health metric into ideal, 
intermediate, or poor categories, as shown in Table 1. Pre-existing CVD was defined by any self-reported previous physician diagnosis of coronary heart disease, myocardial infarction, heart failure or stroke. In defining healthy diet, we used the following 5 components: 1 ) with cereals and legumes as the basic food; 2$) \geqslant 500 g$ (1 “Jin”) vegetables and fruits/day; 3) <100g (2 “Liang”) red meat/day; 4) regular (in most weeks) intake of unprocessed fish and/or soybean products; and 5) preference for non-salty food, in accordance with the current "Dietary Guidelines for Chinese Residents” [17]. Because in most participating centers of the present study, subjects who identified themselves as "heavy manual worker" were not required to further report their physical activity, therefore, for the assessment of physical activity, in addition to calculate participant's weekly physical activity time, we defined all subjects who answered "yes" to the question: "Does your job engaged mostly in heavy manual/physical work?” into "heavy manual worker” and classified them into the “ideal” category. Evaluation of physical activity includes questions about type and frequency of physical activity at work and during leisure time.

We defined “ideal” cardiovascular health as meeting all 7 ideal components of cardiovascular health, " intermediate” cardiovascular health as with at least 1 intermediate metric and no poor metrics, and "poor" cardiovascular health as having at least 1 poor health metric, in accordance with the AHA's construct [6].

\section{Statistical Analyses}

Continuous variables were described by means \pm SDs and compared by t tests or 
corresponding nonparametric tests based on distributional properties. Categorical variables were described by percentages and compared by chi square tests. Because of the number of subjects exceeding one million, subgroup analyses by age, sex and region were conducted for the simplicity of data analyses. Adjusted prevalence of ideal cardiovascular health metrics in all study subjects was standardized to the age and sex distribution for Chinese adults in the year 2010. All data was analyzed with SAS 9.3 for Windows (SAS Institute Inc, Cary, NC).

\section{Results}

\section{Characteristics of study population}

The socioeconomic and clinical characteristics of the 1,012,418 study subjects are shown in Table 2, 54\% of them were male and $46 \%$ were female, $46 \%$ were from South China and 54\% from North China. The majority of the subjects were non-manual workers. The mean age was 42.4 years in male and 43.1 years in female. A total of 13,674 (1.35\%) subjects reported pre-existing CVD. The average systolic blood pressure was $123.4 \mathrm{mmHg}$ in male and $121.3 \mathrm{mmHg}$ in female. Mean total serum cholesterol level was $175.6 \mathrm{mg} / \mathrm{dl}$ in men and $181.4 \mathrm{mg} / \mathrm{dl}$ in women. About $5 \%$ subjects reported use of anti-hypertensive medication, $1.3 \%$ reported use of hypoglycemic drugs and 1\% of lipid lowering drugs. More men had an education level beyond college.

\section{Distribution of ideal cardiovascular health metrics}

As shown in table 1 , of the total study subjects, those who had ideal levels of 
individual cardiovascular health metrics ranged from $74.2 \%$ (smoking) to $7.2 \%$ (diet). As for smoking, body mass index and diet, more women met ideal levels of each metric than men did. However, as for physical activity, total cholesterol, blood pressure, and fasting serum glucose, the proportions of ideal metrics in males tended to be larger than those in females.

Table 3 shows the distribution of ideal cardiovascular health metrics among the study subjects. Overall, only $0.6 \%$ men and $2.6 \%$ women met all ideal cardiovascular metrics. Of all subjects, about $39.0 \%$ met 5 or more metrics. As expected, the percentages of those meeting 5 or more metric decreased with age in both sex. In both men and women, more subjects from South China met 5, 6, or 7 ideal cardiovascular metrics than those from the North.

\section{Prevalence of ideal, intermediate and poor cardiovascular health status}

Table 4 shows the prevalence of ideal, intermediate and poor cardiovascular health of the total study subjects and of the sex, age and region subgroups. Of all subjects, the prevalence of having "ideal”, “intermediate” and "poor” cardiovascular health was 1.5\%, 33.9\%, and 64.6\%, respectively. The majority of men had poor cardiovascular health, while about half of the women had "intermediate" cardiovascular health. The percentages of subjects who had "poor” cardiovascular health increased with age, and were higher in North China participants.

In additional analysis, we hypothesized that all men had quit smoking for more than 12 months, then $1.4 \%$ of them would have had "ideal" and $73.2 \%$ had "poor" 
cardiovascular health.

\section{Comparison with ARIC study cohort}

To provide a context for our results, we compared the proportions of those at different categories of cardiovascular health between our study subjects who were 45-64 years old and those of the ARIC (Atherosclerosis Risk in Communities) study cohort. As shown in Fig 2, the proportions of our study subjects who met 5, 6 and 7 ideal metrics were higher than those of the ARIC cohort population. Our study subjects had more ideal health status $(1.1 \%$ vs. $0.1 \%)$ with relatively less had poor health status $(75.7 \%$ vs. $82.5 \%)$.

\section{Discussion}

The present study examined a relatively "healthier" Chinese population, as reflected by the lower prevalence of major cardiovascular risk factors including hypertension, diabetes, hypercholesterolemia and smoking, in our study subjects comparing to those recently obtained from nationally representative samples [11, 18-20]. However, we still found a disappointingly low proportion of people who had "ideal" health: the age and sex-adjusted prevalence of ideal cardiovascular health, as defined by the AHA, was less than $2 \%$, while almost $60 \%$ had "poor" cardiovascular health. Although our study population seemed to have "better" cardiovascular health, as compared to the 2 community-based US populations [7,8] and the 2003 to 2008 National Health and Nutrition Examination Surveys participants [9], our results again highlight the importance of national and individual efforts to quell the emerging epidemic of CVD 
in China, particularly when we consider that the community-based Chinese adults may have worse cardiovascular health status than participants in the present study.

Women had better cardiovascular health profile than men, and this is consistent with a recent similar report on the cardiovascular health status in US adults [9]. The age-adjusted prevalence of ideal cardiovascular health in women was almost 4 times of that in men. The most important reason for this strikingly sex difference was the much higher prevalence of cigarette smoking in men than in women. Actually, if presumed that all men in our study subjects had quit smoking, the prevalence of ideal cardiovascular health would increase from $0.6 \%$ to $1.4 \%$, and poor health decreased from $80.2 \%$ to $73.2 \%$.

The amount of daily or weekly intake of fish, whole grain, sodium and added sugar of our study population were not available from the questionnaires, and the dietary metrics we used for the present study are based on the recommendations of the Chinese Society of Nutrition in its official dietary guideline, which have been adapted by current CVD prevention guidelines. Traditional Chinese diet, high in vegetables and whole grains but low in animal products, is associated with a low risk of CVD [21]. Although most of these traditional Chinese dietary traits are still being maintained, some marked changes are occurring, such as increased animal food and edible oil consumption, concomitant with the change in lifestyle in China in the past 20 years [22, 23]. Similar to those findings from the US populations, we also found that ideal health diet was the least prevalent CV health component. 
Prevalence of leisure-time physical activity is low in China [24, 25], while non-recreational physical activities including household, occupational and transport activities in adult Chinese have declined rapidly during the last 2 decades, largely due to the urbanization of China [26]. We found that less than one third of the study subjects reported physical activities at goal level, of them half were "heavy manual worker”. Our data highlight the importance of promoting physical activity in the workplace, at home, for transit and via exercise in China.

Several limitations of our study warrant consideration. First, our study participants were not representative sample of Chinese adults but those health examinees and therefore were subject to healthy volunteer biases. The cardiovascular health status may actually be worse in a more general Chinese adult population. Second, except those of fruits and vegetables, quantitative data of the consumption of other nutritional components, including fish, whole grain, sodium and sugar recommended in the diet metrics by AHA were not available in the present study, we used mostly “descriptive” metrics for the diet assessment, which may result in inflated prevalence of "healthy diet". Last, the study subjects in this study were limited to young and middle-aged groups ( $<65$ years), while a significant number of participants with older ages were excluded from the analysis. Lower prevalence of ideal blood pressure and total cholesterol could be observed in this age group, as noticed by Shay et al's study [9]. Thus, our findings should be interpreted in light of this limitation.

In conclusion, our study indicates that about two-thirds adult Chinese urban 
populations have "poor" cardiovascular health, and very few have "ideal" health status. Comprehensive individual and population-based interventions must be developed to improve cardiovascular health status in China. 


\section{Acknowledgements}

This study was supported by the National Key Technology R\&D Program of China (No.2008BAI52B04). The authors of this manuscript thank the many investigators and participants who contributed to the China Health Examination Database. The authors have certified that they comply with the Principles of Ethical Publishing in the International Journal of Cardiology [27]. 


\section{References}

1) He J, Gu D, Wu X, Reynolds K, Duan X, Yao C, Wang J, Chen CS, Chen J, Wildman RP, Klag MJ, Whelton PK: Major causes of death among men and women in China. N Engl J Med, 2005;353:1124 -1134

2) Moran A, Gu D, Zhao D, Coxson P, Wang YC, Chen CS, Liu J, Cheng J, Bibbins-Domingo K, Shen YM, He J, Goldman L: Future cardiovascular disease in china: markov model and risk factor scenario projections from the coronary heart disease policy model-china. Circ Cardiovasc Qual Outcomes, 2010;3:243-52

3) Zhang $\mathrm{XH}, \mathrm{Lu} \mathrm{ZL}$, Liu L: Coronary heart disease in China. Heart, 2008;94:1126-31.

4) Chinese Society of Cardiology of Chinese Medical Association, Editorial Board of Chinese Journal of Cardiology. Chinese guidelines for prevention of cardiovascular diseases. Chinese Journal of Cardiology, 2011; 39: 3-22.

5) Liu LS; Writing Group of 2010 Chinese Guidelines for the Management of Hypertension. 2010 Chinese guidelines for the management of hypertension. Zhonghua Xin Xue Guan Bing Za Zhi. 2011 Jul;39(7):579-615.

6) Lloyd-Jones DM, Hong Y, Labarthe D, et al. Defining and setting national goals for ardiovascular health promotion and disease reduction: the American Heart Association's strategic Impact Goal through 2020 and beyond. Circulation 2010;121:586-613.

7) Bambs C, Kip KE, Dinga A, Mulukutla SR, Aiyer AN, Reis SE. Low 
prevalence of “ideal cardiovascular health” in a community-based population: the Heart Strategies Concentrating on Risk Evaluation (Heart SCORE) study. Circulation. 2011;123:850-857.

8) Folsom AR, Yatsuya H, Nettleton JA, et al., for the ARIC Study Investigators. Community prevalence of ideal cardiovascular health, by the American Heart Association definition, and relationship with cardiovascular disease incidence. J Am Coll Cardiol 2011;57:1690-6.

9) Shay CM, Ning H, Allen NB, et al. Status of Cardiovascular Health in US Adults: Prevalence Estimates From the National Health and Nutrition Examination Surveys (NHANES) 2003-2008. Circulation. 2012;125:45-56.

10) Wu HY, Wu LX, Zen Q, Qiang DC. Do currently recommended risk prediction tools help primary prevention of cardiovascular disease in Chinese population? Int J Cardiol. 2011;146:299-301.

11) Wu Y, Huxley R, Li L, et al. Prevalence, awareness, treatment, and control of hypertension in China: data from the China National Nutrition and Health Survey 2002. Circulation. 2008;118(25):2679-2686.

12) Lloyd-Jones D, Adams RJ, Brown TM, et al. Heart disease and stroke statistics, 2010 update: a report from the American Heart Association. Circulation. 2010;121:e46-e215.

13) Artinian NT, Fletcher GF, Mozaffarian D, et al. Interventions to promote physical activity and dietary lifestyle changes for cardiovascular risk factor reduction in adults: a scientific statement from the American Heart 
Association. Circulation. 2010;122:406-441.

14) Chiuve SE, McCullough ML, Sacks FM, Rimm EB. Healthy lifestyle factors in the primary prevention of coronary heart disease among men: benefits among users and nonusers of lipid-lowering and antihypertensive medications. Circulation. 2006;114:160 -167.

15) Kurth T, Moore SC, Gaziano JM, et al. Healthy lifestyle and the risk of stroke in women. Arch Intern Med. 2006;166:1403-1409.

16) Chiuve SE, Rexrode KM, Spiegelman D, Logroscino G, Manson JE, Rimm EB. Primary prevention of stroke by healthy lifestyle. Circulation. 2008;118:947-954.

17) Ge KY. The transition of Chinese dietary guidelines and the food guide pagoda. Asia Pacific Journal of Clinical Nutrition20. 3 (Sep 2011): 439-446.

18) Yang W, Lu J, Weng J, et al. China National Diabetes and Metabolic Disorders Study Group: Prevalence of diabetes among men and women in China. N Engl J Med 2010, 362:1090-1101.

19) Wang S, Xu L, Jonas JB, You QS, Wang YX, Yang H. Prevalence and associated factors of dyslipidemia in the adult Chinese population. PLoS One 2011 Mar 10;6(3):e17326.

20) Li Q, Hsia J, Yang G. Prevalence of smoking in China in 2010. N Engl J Med 2011; 364:2469-2470.

21) Willett WC. Diet and health: what should we eat? Science1994; 264:532-537.

22) F.Y. Zhai, Y.N. He, G.S. Ma, Y.P. Li, Z.H. Wang and Y.S. Hu et al., Study on 
the current status and trend of food consumption among Chinese population, Acta Nutrimenta Sinica 26 (2005), pp. 485-488.

23) Zhai F, Wang H, Du S, He Y, Wang Z, Ge K, Popkin BM. Prospective study on nutrition transition in China. Nutr Rev. 2009 May;67 Suppl 1:S56-61.

24) Jurj AL, Wen W, Gao YT, et al. Patterns and correlates of physical activity: a cross-sectional study in urban Chinese women. BMC Public Health 2007;7:213.

25) Lee SA, Xu WH, Zheng W, et al. Physical activity patterns and their correlates among Chinese men in Shanghai. Med Sci Sports Exerc 2007;39(10):1700-1707.

26) Ng SW, Norton EC, Popkin BM. Why have physical activity levels declined among Chinese adults? Findings from the 1991-2006 China Health and Nutrition Surveys. Soc Sci Med. 2009 Apr;68(7):1305-14. Epub 2009 Feb 18.

27) Coats AJ. Ethical authorship and publishing. Int J Cardiol 2009;131:149-50. 
Table 1. Cardiovascular health metrics definition and their distribution among

\section{study men and women}

\begin{tabular}{|c|c|c|c|c|c|}
\hline $\begin{array}{l}\text { Health } \\
\text { metrics }\end{array}$ & & Definition & $\begin{array}{l}\text { Total sample, } \% \\
(\mathrm{n}=1,012,418)\end{array}$ & $\begin{array}{l}\text { Men, \% } \\
(n=546,485)\end{array}$ & $\begin{array}{l}\text { Women, \% } \\
(\mathrm{n}=465,933)\end{array}$ \\
\hline \multirow[t]{3}{*}{ Smoking } & Ideal & Never or quit $>12$ months & 74.2 & 55.7 & 96.3 \\
\hline & Intermediate & Former, quit $<12$ months & 1.7 & 3.2 & 0.2 \\
\hline & Poor & Current & 24.1 & 41.1 & 2.4 \\
\hline Body mass & Ideal & $<25 \mathrm{~kg} / \mathrm{m}^{2}$ & 66.9 & 66.3 & 67.6 \\
\hline \multirow[t]{2}{*}{ index } & Intermediate & $25-29.9 \mathrm{~kg} / \mathrm{m}^{2}$ & 25.2 & 26.4 & 23.8 \\
\hline & Poor & $\geqslant 30 \mathrm{~kg} / \mathrm{m}^{2}$ & 7.9 & 7.3 & 8.6 \\
\hline \multirow[t]{3}{*}{ Diet } & Ideal & 4-5 components & 7.2 & 5.6 & 9.2 \\
\hline & Intermediate & 2-3 components & 67.4 & 63.0 & 72.6 \\
\hline & Poor & $0-1$ components & 26.4 & 31.4 & 18.2 \\
\hline \multirow[t]{4}{*}{$\begin{array}{l}\text { Physical } \\
\text { activity }\end{array}$} & Ideal & $\begin{array}{l}\text { "heavy manual worker”, } \\
\text { and/or }\end{array}$ & 31.7 & 34.6 & 28.3 \\
\hline & & $\begin{array}{l}\geqslant 150 \mathrm{~min} / \mathrm{wk} \text { moderate } \\
\text { intensity or } 75 \mathrm{~min} / \mathrm{wk} \\
\text { vigorous intensity or } 150 \\
\text { min/wk moderate }+ \\
\text { vigorous }\end{array}$ & & & \\
\hline & Intermediate & $\begin{array}{l}\text { 1-149 } \mathrm{min} / \mathrm{wk} \text { moderate } \\
\text { intensity or } 1-74 \mathrm{~min} / \mathrm{wk} \\
\text { vigorous intensity or } \\
1-149 \mathrm{~min} / \mathrm{wk} \text { moderate + } \\
\text { vigorous }\end{array}$ & 44.5 & 41.2 & 48.3 \\
\hline & Poor & None & 23.8 & 24.2 & 23.4 \\
\hline \multirow[t]{3}{*}{$\begin{array}{l}\text { Total } \\
\text { cholesterol }\end{array}$} & Ideal & $\begin{array}{l}<200 \quad \mathrm{mg} / \mathrm{dl} \text {, without } \\
\text { medication }\end{array}$ & 63.7 & 65.6 & 61.4 \\
\hline & Intermediate & $\begin{array}{l}200-239 \mathrm{mg} / \mathrm{dl} \text { or treated } \\
\text { to }<200 \mathrm{mg} / \mathrm{dl}\end{array}$ & 33.2 & 31.5 & 35.2 \\
\hline & Poor & $\geqslant 240 \mathrm{mg} / \mathrm{dl}$ & 3.1 & 2.9 & 3.4 \\
\hline \multirow[t]{3}{*}{$\begin{array}{l}\text { Blood } \\
\text { pressure }\end{array}$} & Ideal & $\begin{array}{l}<120 /<80 \mathrm{~mm} \mathrm{Hg} \text {, without } \\
\text { medication }\end{array}$ & 44.8 & 49.6 & 47.0 \\
\hline & Intermediate & $\begin{array}{l}\text { SBP } 120-139 \text { or } \mathrm{DBP} \\
80-89 \mathrm{~mm} \mathrm{Hg} \text { or treated } \\
\text { to goal }\end{array}$ & 39.1 & 36.5 & 37.9 \\
\hline & Poor & $\begin{array}{l}\mathrm{SBP} \geqslant 140 \text { or } \mathrm{DBP} \geqslant 90 \\
\mathrm{~mm} \mathrm{Hg}\end{array}$ & 16.1 & 13.9 & 15.1 \\
\hline \multirow{3}{*}{$\begin{array}{l}\text { Fasting } \\
\text { serum } \\
\text { glucose }\end{array}$} & Ideal & $<100 \mathrm{mg} / \mathrm{dl}$ & 55.5 & 56.7 & 54.2 \\
\hline & Intermediate & $\begin{array}{l}100-125 \mathrm{mg} / \mathrm{dl} \text { or treated } \\
\text { to goal }\end{array}$ & 40.3 & 39.2 & 41.5 \\
\hline & Poor & $\geqslant 126 \mathrm{mg} / \mathrm{dl}$ & 4.2 & 4.1 & 4.3 \\
\hline
\end{tabular}


Table 2. Characteristics of study population

\begin{tabular}{|c|c|c|c|}
\hline & Men & Women & Total \\
\hline All subjects, $n$ & 546,485 & 465,933 & $1,012,418$ \\
\hline Mean age, $y$ & $42.4 \pm 6.6$ & $43.1 \pm 6.1$ & $42.7 \pm 6.4$ \\
\hline Mean systolic blood pressure, $\mathrm{mmHg}$ & $123.4 \pm 16.2$ & $121.3 \pm 18.8$ & $122.4 \pm 17.4$ \\
\hline Mean body mass index, $\mathrm{kg} / \mathrm{m}^{2}$ & $23.6 \pm 2.2$ & $23.4 \pm 2.6$ & $23.5 \pm 2.4$ \\
\hline Mean serum total cholesterol, mg/dl & $175.6 \pm 29.2$ & $181.4 \pm 28.6$ & $178.3 \pm 29.0$ \\
\hline Mean fasting serum glucose, $\mathrm{mg} / \mathrm{dl}$ & $96.4 \pm 13.7$ & $96.6 \pm 14.8$ & $96.5 \pm 14.4$ \\
\hline Current smoking, n (\%) & 224605(41.1) & $11182(2.4)$ & 249055(24.6) \\
\hline Self-reported CVD, n (\%) & $7651(1.4)$ & $6058(1.3)$ & 13,709 \\
\hline Diabetes mellitus, n (\%) & $22952(4.2)$ & 20501(4.4) & 43453(4.3) \\
\hline Use of anti-hypertensive drug, n (\%) & $30057(5.5)$ & $19103(4.1)$ & $49160(4.9)$ \\
\hline Use of hypoglycemic drugs, n (\%) & $6558(1.2)$ & $6524(1.4)$ & 13082(1.3) \\
\hline Use of lipid-lowering drug, n (\%) & $6013(1.1)$ & $3727(0.8)$ & $9740(1.0)$ \\
\hline \multicolumn{4}{|l|}{ Area, n (\%) } \\
\hline South China & 262313(48.0) & 204079(43.8) & 466392(46.1) \\
\hline North China & 284172(52.0) & 261854(56.2) & $546026(53.9)$ \\
\hline \multicolumn{4}{|l|}{ Education, n (\%) } \\
\hline Secondary school or less & 84159(15.4) & 87129(18.7) & 171288(16.9) \\
\hline High school & 277614(50.8) & $243217(52.2)$ & 520831(51.4) \\
\hline College or more & 184712(33.8) & 135587(29.1) & 320299(31.6) \\
\hline \multicolumn{4}{|l|}{ Occupation, n (\%) } \\
\hline Manual worker & $89624(16.4)$ & $66162(14.2)$ & 155786(15.4) \\
\hline Non-manual worker & 367784(67.3) & 358303(76.9) & 726087(71.7) \\
\hline Other & 89077(16.3) & 41468(8.9) & $130545(6.2)$ \\
\hline
\end{tabular}


Table 3. Distribution (prevalence, \%) of ideal cardiovascular health metrics in men and women, by age and region subgroups

\begin{tabular}{|c|c|c|c|c|c|c|c|c|}
\hline \multirow[t]{2}{*}{ Subject group } & \multicolumn{8}{|c|}{ No. of ideal health metrics present } \\
\hline & 7 & 6 & 5 & 4 & 3 & 2 & 1 & 0 \\
\hline \multicolumn{9}{|l|}{ Total } \\
\hline Unadjusted & 1.5 & 12.3 & 25.3 & 21.5 & 25.1 & 9.2 & 4.8 & 1.0 \\
\hline Age and sex adjusted & 1.9 & 12.8 & 26.1 & 22.1 & 23.5 & 8.9 & 4.1 & 0.8 \\
\hline \multicolumn{9}{|l|}{ Men } \\
\hline Overall & 0.6 & 11.5 & 21.4 & 21.5 & 27.0 & 10.5 & 6.9 & 1.4 \\
\hline \multicolumn{9}{|l|}{ Age, y } \\
\hline $20-29$ & 1.4 & 14.2 & 30.4 & 26.6 & 20.2 & 4.4 & 2.5 & 0.3 \\
\hline $30-39$ & 0.6 & 13.8 & 25.6 & 23.4 & 24.6 & 12.1 & 3.1 & 1.2 \\
\hline $40-49$ & 0.5 & 11.9 & 23.4 & 19.8 & 26.2 & 10.0 & 6.4 & 1.8 \\
\hline $50-59$ & 0.4 & 11.2 & 19.3 & 21.7 & 28.2 & 8.9 & 8.8 & 1.5 \\
\hline $60-65$ & 0.4 & 8.8 & 15.3 & 21.1 & 30.5 & 14.4 & 9.2 & 1.3 \\
\hline \multicolumn{9}{|l|}{ Region } \\
\hline South & 0.7 & 13.6 & 22.6 & 23.8 & 22.7 & 9.2 & 6.3 & 1.0 \\
\hline North & 0.5 & 8.4 & 20.2 & 19.2 & 31.3 & 11.8 & 7.5 & 1.8 \\
\hline \multicolumn{9}{|l|}{ Women } \\
\hline Overall & 2.6 & 13.8 & 26.3 & 22.4 & 23.3 & 8.2 & 2.6 & 0.6 \\
\hline \multicolumn{9}{|l|}{ Age, $y$} \\
\hline $20-29$ & 5.8 & 17.5 & 30.5 & 25.3 & 16.2 & 3.4 & 2.1 & 0.2 \\
\hline $30-39$ & 4.2 & 16.9 & 27.4 & 22.8 & 19.6 & 5.6 & 2.6 & 0.2 \\
\hline $40-49$ & 2.2 & 14.4 & 26.8 & 20.6 & 23.2 & 8.5 & 3.8 & 0.4 \\
\hline $50-59$ & 1.8 & 12.1 & 23.7 & 21.1 & 24.6 & 9.1 & 7.2 & 1.1 \\
\hline $60-65$ & 1.6 & 9.7 & 21.2 & 22.6 & 25.1 & 11.2 & 8.1 & 1.0 \\
\hline \multicolumn{9}{|l|}{ Region } \\
\hline South & 2.7 & 19.1 & 32.3 & 21.7 & 14.1 & 7.3 & 2.2 & 0.6 \\
\hline North & 2.5 & 15.6 & 28.4 & 22.9 & 18.2 & 8.8 & 3.0 & 0.6 \\
\hline
\end{tabular}


Table 4. Prevalence of ideal, intermediate and poor cardiovascular health in men and women, by age and region subgroups

\begin{tabular}{|c|c|c|c|}
\hline \multirow[t]{2}{*}{ Subject group } & \multicolumn{3}{|c|}{ Prevalence, \% } \\
\hline & Ideal & Intermediate & Poor \\
\hline \multicolumn{4}{|l|}{ Total } \\
\hline Unadjusted & 1.5 & 33.9 & 64.6 \\
\hline Age and sex adjusted & 1.9 & 39.5 & 58.6 \\
\hline \multicolumn{4}{|l|}{ Men } \\
\hline \multicolumn{4}{|l|}{ Overall } \\
\hline Unadjusted & 0.6 & 17.4 & 82.0 \\
\hline Age-adjusted & 0.8 & 24.8 & 74.4 \\
\hline \multicolumn{4}{|l|}{ Age, y } \\
\hline $20-29$ & 1.4 & 32.6 & 66.0 \\
\hline 30-39 & 0.6 & 24.3 & 75.1 \\
\hline $40-49$ & 0.5 & 18.7 & 80.8 \\
\hline $50-59$ & 0.4 & 14.4 & 85.2 \\
\hline $60-65$ & 0.4 & 9.6 & 90.0 \\
\hline \multicolumn{4}{|l|}{ Region } \\
\hline South & 0.7 & 20.9 & 78.4 \\
\hline North & 0.5 & 13.9 & 85.6 \\
\hline \multicolumn{4}{|l|}{ Women } \\
\hline \multicolumn{4}{|l|}{ Overall } \\
\hline Unadjusted & 2.6 & 53.2 & 44.2 \\
\hline Age-adjusted & 3.1 & 54.2 & 42.7 \\
\hline \multicolumn{4}{|l|}{ Age, y } \\
\hline $20-29$ & 5.8 & 68.4 & 25.8 \\
\hline 30-39 & 4.2 & 62.1 & 33.7 \\
\hline $40-49$ & 2.2 & 54.7 & 43.1 \\
\hline $50-59$ & 1.8 & 48.5 & 49.7 \\
\hline $60-65$ & 1.6 & 39.3 & 59.1 \\
\hline \multicolumn{4}{|l|}{ Region } \\
\hline South & 2.7 & 54.4 & 42.9 \\
\hline North & 2.5 & 51.9 & 45.6 \\
\hline
\end{tabular}


